SOI: $1.1 /$ TAS DOI: $10.15863 /$ TAS

International Scientific Journal Theoretical \& Applied Science

p-ISSN: 2308-4944 (print) e-ISSN: 2409-0085 (online)

Year: $2018 \quad$ Issue: 02 Volume: 58

Published: $11.02 .2018 \quad$ http://T-Science.org

SECTION 29: Literary studies. Folklore.

Translation.
Dilfuza Sayidmahamadzhanovna Saiidyrakhimova

Candidate of Philology, Docent

Head of the Department of English Philology,

Kyrgyz-Uzbek University,

Osh city, Kyrgyz Republic

ossu.oms@gmail.com

Dilbar Mamatovna Zhakypova

Postgraduate student of the Department of

English Philology,

Kyrgyz-Uzbek University,

Osh city, Kyrgyz Republic

ossu.oms@gmail.com

\title{
GENERAL THEORETICAL ASPECTS IN SYNCHRONICAL TYPOLOGICAL LEARNING OF ENGLISH ADVERBS
}

\begin{abstract}
Questions of the parts of speech (further PS) - among the central problems of the theory of grammar. The study of the problems of the PS has its deep historical history (from the ancient times of the history of linguistics). Despite this, many of the theoretical problems of the PS have not yet been fully developed. Differences of scientists are observed even in the classification of the PS. Unambiguously, there are no specific places for individual lexical and grammatical categories in the general system, one of them is an adverb - "a hybrid category, like gerund and participle" (V.V. Vinogradov).

Key words: parts of speech, classification, hybrid category, gerunds, lexico-grammatical category, state actions.

Language: Russian

Citation: Saiidyrakhimova DS, Zhakypova DM (2018) GENERAL THEORETICAL ASPECTS IN SYNCHRONICAL TYPOLOGICAL LEARNING OF ENGLISH ADVERBS. ISJ Theoretical \& Applied Science, 02 (58): 16-19.
Soi: http://s-o-i.org/1.1/TAS-02-58-5
Doi: crossef https://dx.doi.org/10.15863/TAS.2018.02.58.5

УДК: 81.132

\section{ОБЩИЕ ТЕОРЕТИЧЕСКИЕ ВОПРОСЫ СИНХРОННО ТИПОЛОГИЧЕСКОГО ИЗУЧЕНИЯ ЯЗЫКОВЫХ ЯВЛЕНИЙ}

Аннотация: Вопросы частей речи (далее ЧР) - в числе центральных проблем теории грамматики. Изучение проблем ЧР имеет свою глубокодавнюю историю (с античных времен истории языкознания). Несмотря на это, многие теоретические проблемы ЧР до сих пор не вполне разработаны. Разногласия ученых наблюдаются даже в классификачии ЧР. Однозначно не определены собственные места отдельных лексико-грамматических категорий в общей системе ЧР, одной из них является наречие «гибридная категория, наподобие деепричастия и причастия» (В.В. Виноградов).

Ключевые слова: части речи, классификация, гибридная категория, деепричастия, лексикограмматическая категория, действия состояния.

\section{Introduction}

Наречия данной семантической группы обозначают цель совершенного (завершенного) или не совершенного (незавершенного) действиясостояния, которые представляются в обоих языках в малом количестве.

\section{Materials and Methods}

В узбекском языке система наречий цели состоит из слов атай, атайин, атайлаб, журтттага, азза-базза, қасддан, заимствованных узбекским языком из таджикского. В таджикском языке наречия цели, кроме слова қасддан, являются производными, образованы посредством суффикса -и (нодони); префиксов бе- (бехуда, бедарак), бар-(барқасд), некоторые из них путем редупликации: дида-ю дониста, дониста-ю нодониста, бемавриду+бомаврид.

Наречия цели лутфан, таъкидан заимствованы в таджикский язык из арабского. Следует отметить, что некоторые наречия в сопоставительно изучаемых языках являются многозначными. Например, наречия типа бехуда, бедарак употребляются и в значении цели, и в значении образа действия. Например, слово бедарак в предложении Уруш вақтида куй 
йигитлар бедарак йуқолди обозначает не цель совершения действия, а образа действия совершения действия -состояния. Подобная же особенность наблюдается в употреблениях слово ноилоч в таджикском языке.

Итак, и семантический план наречий представляет собой своеобразную систему, что характерно для категории наречий и узбекского, и таджикского языков.

1. Части речи являются одной из дискуссионных и актуальнейших проблем языкознания. Изучение вопросов частей речи имеет свою глубокую историю, являлись объектом науки о языке с античных времен (древнеиндийское, латино-греческое, арабское языкознание). Однако отдельные вопросы, связанные с проблемами ЧР остаются не решенными и ныне наблюдается неоднозначность даже в их классификации.

Неоднозначны точки зрения специалистов и в отношении лексико-грамматических категорий общей системы ЧР, одной из которых является лексико-грамматическая категория наречия.

Наречием образуются признаки и качества действия, состояния. Признак и качества значения общеграмматическое, свойственные и другим лексико-грамматическим категориям системы ЧР. С точки зрения обозначения признаки, качества к наречиям приближаются лексико-грамматические категории прилагательных и глаголов. Значение признака, качества обозначают и отдельные существительные типа вишт, (вишт девор), темир (темир дарвоза), кумуш (кумуи қошиқ) и т.д. Однако это не значит, что семантические планы наречия, прилагательного, глагола и отдельных существительных не отличаются друг от друга. Все они отличаются друг от друга в отношении характера обозначаемых ими значениями. Так, наречием обозначаются признаки и качества действия, состояния; прилагательным - признаки и качества предмета, явления; глаголом - признаки и качества предмета и движения, действий. Значения наречия - это признак, свойства признака состояния . Значение прилагательного - признак, свойство статического (недействующего) характера, а значение глагола признак процессульности, динамического характера. В чем и заключаются различия между семантическими планами наречия, прилагательного и глагола.

Наречия в грамматико-семантическом плане наиболее близки к прилагательным. Но это не значит, что они не различимы друг от друга. Наречие в семантико-грамматическом плане зависимо от глагола, а прилагательное-от существительного. Значения наречия или прилагательного реализуются синтагматическим окружение, в котором в качестве партнеров наречия выступают глаголы, а партнерами прилагательных выступают существительные.

Таким образом, реализация всякого значения, и семантического, и грамматического плана, зависит от синтагматической особенности лексем. Синтагматические возможности глагола осуществляются при их связи с существительными. Значит, значение глагола зависит от значения существительного, которое реализуется через предикативную конструкцию.

2. Грамматические значения первоначально бывают а обсолютно гетерогенными и абсолютно гомогенными; первое из них характерно для имен существительных, а второе для наречий. Между гетерогенными и гомогенными грамматическими значениями функционируют и значения для других, кроме существительного и наречия, знаменательных частей речи. В промежуточных грамматических значениях синхронносинкретично совмещаются признаки и гетерогенных, и гомогенных грамматических значениях, которые не характерны для грамматических значений существительного и наречия. Отсюда ясно, что промежуточные грамматические значения - это грамматические значения прилагательных, глаголов, которые могут называться гетерогенно-гомогенными значениями.

Гетерогенно-гомогенные грамматические значения характеризуются тем что они являются гетерогенными, а также и гомогенными по отношению к грамматическим значениям других лексико-грамматических категорий. Так, например, грамматическое значение прилагательного - гомогенное значение отношении грамматического значения имени существительного, а гетерогенное оно в отношении грамматического значения наречия . Подобную же характеристику имеет и в грамматическое значение глагола. Грамматическое значение глагола является гомогенным в отношении грамматического значения существительного, а гетерогенным- в отношении грамматического значения наречия.

Абсолютно гетерогенный характер грамматического значения имен существительных характеризуется тем, что оно абсолютно независимое значение, оно не подчиняется значениям ЧР.

Абсолютно гомогенный характер грамматического значения наречия объясняется тем, что оно - только подчиненное. Оно зависимо от грамматических значений глагола и прилагательного, реже - существительного. Грамматическим значениям наречия не подчиняются значения каких- либо лексикограмматических категорий системы ЧР.

3. Своеобразный характер носит и формально-лингвистический план наречий. 
Первоначально образовались существительное и глагол. Прилагательное и наречие после них. Это обясняется тем, что человечеством прежде всего ощущались объективный мир и его предметы, явления, а потом их действия и состояния. Ощущение признаков, качеств осуществлялось после всех этих. Поэтому и названия этих явлений появились самомыми последними в качесвтве прилагательных и наречий. Появление глаголов, прилагательных и наречий после существительных отмечается со стороны А.А.Потебни и И.М.Пешковского. Имеются разные классификации ЧР, некоторые из них носят традиционный характер. Однако, среди них есть и, нетрадиционные. Согласно одно из таких классификаций, ЧР делятся на две группы: автосемантические и синсемантические. Все знаменательные ЧР отнесены к первой группе, все служебные - ко второй.

4. Разделение на группы автосемантических и синсемантических характерно и для систем знаменательных ЧР, где существительное и глагол рассматриваются автосемантическими, а остальные - прилагательное, числительное, наречие-синсемантическими ЧР. Ясно, что местоимения занимают промежуточную зонумежду автосемантическими и синсемантическими знаменательными ЧР. Те местоимения, которыми осуществляются функция и значения существительных и глаголов, относятся к автосемантическим группам; те местоимения, которыми осуществляются значения и функции других ЧР к синсемантическим группам.

5. Наречия в предложении функционируют как обстоятельства, что является основной их синтаксических функцией, с точки зрения которой определяется их изосемичная функция (Г.А.Золотова). Неизосемичная функция наречий наблюдается, если они функционируют в предложении в качестве иного члена предложения, кроме обстоятельства. Неизосемичная функция наречий в предложении осуществляется под влиянием отдельных разновидностей транспозиции (конверсии) субстантивации, адъективизации прономинализации и вербализации. Всем этим определяется своеобразная сложность категории наречия.

6. Наречиям свойственна система собственного словообразования, как это наблюдается в системах имен существительных, прилагательных и глаголов. В словообразовательной системе наречия важную роль играет аффиксация и композиция, которые являются основными и ведущими способами при образовании новых лексических единиц категории наречия. Наблюдаются случаи, когда слова, других Ч.Р в составе которых имеются морфологические показатели словоизменение и формообразования, рассматриваются в качестве наречия (тугсатдан , қуққиисдан, бирдан, бирданига $u$ т.д.), что не характерно для систем других ЧР.

7. При сопоставительном изучении наречий узбекского и таджикского языков выяснилось то, что между системами категорий наречий узбекского и таджикского языков, имеются определённые сходства и различия, которые характеризуются в отношении, в основном, характера ин грамматического строя. В лексиках таджикского и узбекского языков имеется общий пласт, который состоит из лексических заимствований арабского происхождения: аввало, азал, ахуён- ахуён , виждонан, воқееан, доимо, доимий, жисмонан, иттифоқ̧о / иттифоқ̧ан, ихтиёран, мажбуран, такроран, тасодифан, тақлидан и т.д.. Некоторые из них в узбекский язык заимствованы через таджикский язык, чем определяется роль таджикского языка в развитии узбекского языка и обогащении его лексики.

Наблюдается сходство между таджикскими и узбекскими языками в отношении образования отдельных сложных, парных и повторных слов. Бу ер-инчо, у ер-он чо, бу тараф-ин тараф,; хуар ер-хуар ер-хуар чо-хуар чо, бугун (бу кун) -имрузз и т.д. Подобное же соответствие характерно и для механизма функционирования способа аффиксации в таджикском и узбекском языках. Суффиксация является одним из ведущих способов словообразования словообразование в обоих языках.

Следует отметить, что эти сходства в системе словообразования узбекского и таджикского языков не значат, что эти языки не отличаются друг от друга. Некоторые производные по составу слова заимствованы в узбекский язык из таджикского. А также модели слвообразовательных структур производных слов типа эщикма-эиик, куัчама-куัча, бирма-бир и др. характерны для образования повторных и парных слов таджикского языка (дам-бадам, дар-бадар), которые заимствованы узбекским языком из таджикского языка.

Одним из основных различий в системе словообразования узбекского и таджикского языков является то, что для таджикского языка характерно образование наречий посредством префиксации и инфиксации, которое отсутствует в системе аффиксального словообразования узбекского языка.

Таджикские и узбекские языки отличаются друг от друга и в отношении характера процесса конъюнкционализации наречий. В узбекском языке при конъюнкционализации образуются послелоги, а в таджикском предлоги. Эти особенности объясняются тем, что узбекский по своему грамматическому строю относится к 
языкам агглютинативного строя, а таджикскийчастично флективного строя.

Таджикский язык является языком с предлогами, а узбекский - языком с послелогами. Предлоги и послелоги - явления разного плана. В языках с предлогами синтаксические отношения (например, объективные релятивные) осуществляются посредством предлогов, а в языках с послелогами, наоборот, посредством послелогов. В узбекском языке процесс конъюниционализации наречий более активен, чем процесс конъюнкционализации наречий в таджикском языке.

\section{Conclusion}

Процесс конъюнкционализации наречий в узбекском языке осуществляется под влиянием определенных законов логики, в которых конъюнкционилизованные послелоги отрицают прежные признаки, которые были свойственными в наречиях. Конъюнкционализация наречий длительный и сложный процесс: первоначально они являлись или существительными, или прилагательными, или глаголами; а потом - наречиями, а потом - послелогами. Послелог - конечный результат процесса конверсии, а также и явление конъюнкционализации и является последней стадией конверсии (транспозиции ). Все эти процессы не характерны для системы предлогов в таджикском языке, чем и определяется различие между наречиями таджикского и узбекского языков.

Различия подобного характера системы наречий этих языков этим ещё не исчерпаны. Дальнейшее изучение их в семантическом плане необходимо и важно. Сравнительное изучение системы наречий и других ЧР важно и необходимо еще и в том смысле, что оно способствует научному осмыслению грамматического строя таджикского и узбекского языков.

Таким образом наречия каждого языка характеризуются своими своеобразовательными грамматическими и семантическими особенностями, изучение которых имеет важное теоретическое и практическое значение.

\section{References:}

1. Avaliani Ju. Ju. (1975) K harakteristike nekotoryh zalogovyh form $\mathrm{v}$ sovremennom tadzhikskom jazyke (v sravnenii s kurdskim jazykom). - Trudy Samarkandskogo gos. un ta im. A. Navoi, novaja serija. Vyp. 269. Samarkand, 1975. -p. 2-20.

2. Avrorin V.A. (1961) Grammatika nanajskogo jazyka. -M., 1961. -p. 177.

3. Andreev I.S. (1945) O tadzhikskom jazyke nastojashhego vremeni. - Materialy po istorii tadzhikov i Tadzhikistana. Stalinabad, Gosizdat pri Sovete narodnyh komissarov Tadzh. SSR, 1945. -p. 56 -57.

4. Anichenko V.V. (1975) Sopostavitel'naja harakteristika leksiki vostochnoslavjanskogo jazykov. - V kn.: VNK - Minsk, 1975. -p. 14 19.

5. Arzumanov S.D., Dzhalilov O. (1969) Zaboni tochiki. Uchebnik tadzhikskogo jazyka dlja vysshih uchebnyh zavedenij. - Dushanbe: Irfon.

6. Buzurgzoda L. (1937) Materialxo ba grammatikai zaboni tochiki. - Inқilobi madani, 1937. № 1. p. $7-15$.
7. Buzurgzoda L., Nijozmuxammadov B. (1946) Grammatikai zaboni tochiki, k. I, Fonetika va morfologija, baroi maktabxoi mijonai nopurra va mijona. -Stalinobod: Nashr. Davl. Toch..

8. Butenko N. P., Suprun A. E.., Titova L.N. (1975) Nekotorye osobennosti associativnoj struktury russkoj i ukrainskoj leksiki. - V.kn.: VNK-Minsk, 1975. -p. 89 -89.

9. Buhorizoda A.L. (1954) Funkcija mestoimennyh suffiksov $\mathrm{v}$ sovremennom tadzhikskom literaturnom jazyke. Avtoref. kand. diss. -Stalinabad.

10. Vajntraub R.M. (1975) Opyt sopostavlenija somaticheskoj frazeologii V slavjanskih jazykah. (K voprosu o sravnitel'nom izuchenii slavjanskoj frazeologii). - Tr. SamGU, 1975, vyp. 288,. Vopr. frazeol., № 9. -M., -p. 157162.

11. Vahek I. (1967) Fonemy i fonologicheskie edinicy. - Prazhskij lingvisticheskij kruzhok. M.. 